Francesco Ballarin. Domitius Culsu sp. nov. (Araneae, Nesticidae), a new troglobiont spider from Italy with notes on Italian nesticids of the genus Domitius Ribera, 2018. Journal of Cave and Karst Studies, v. 82, no. 2, p. 82-94. DOI:10.4311/2019LSC0103

\title{
DOMITIUS CULSU SP. NOV. (ARANEAE, NESTICIDAE), A NEW TROGLOBIONT SPIDER FROM ITALY WITH NOTES ON ITALIAN NESTICIDS OF THE GENUS DOMITIUS RIBERA, 2018
}

\author{
Francesco Ballarin ${ }^{1,2}$
}

\begin{abstract}
Seven species from the spider family Nesticidae are currently known for the Italian fauna. Three Italian nesticids belong to the newly-established genus Domitius Ribera, 2018. All these species show a restricted distribution along the Apennine mountain chain and deep adaptation to cave life. Herein, a fourth species, $D$. culsu sp. nov. from a single cave in Northern Apennines is described. Detailed illustrations and diagnosis of the new species are provided. Molecular and morphological analysis of both sexes of $D$. culsu sp. nov. supports the validity of the new species and its close relationship with the other Domitius species from the same geographical area. A close affinity with the species distributed in the Iberian Peninsula is also observed. The potential susceptibility of $D$. culsu sp. nov. to external disturbance, and its extremely limited distribution, makes this spider of interest for conservation.
\end{abstract}

\section{INTRODUCTION}

Nesticidae Simon, 1894 is a small family of spiders with a worldwide distribution. Currently, 278 species and 16 genera are recognized (World Spider Catalog, 2020). At temperate latitudes, nesticids mostly occur in dark, damp environments such as caves, often showing high levels of endemism. Previously, the majority of nesticid species were included in the genus Nesticus Thorell, 1869. Nesticus has recently been partially revised (Lin et al., 2016; Pavlek and Ribera, 2017; Ribera, 2018) and several of its European species moved to different genera (e.g. Typhlonesticus Kulczyński, 1914, Kryptonesticus Pavlek and Ribera, 2017, Domitius Ribera, 2018).

Eight nesticid species belonging to five genera are currently known in Italy: Domitius menozzii (di Caporiacco, 1934), D. sbordonii (Brignoli, 1979), D. speluncarum (Pavesi, 1873), Eidmannella pallida (Emerton, 1875), Kryptonesticus eremita (Simon, 1880), Nesticus cellulanus (Clerck, 1757), Typhlonesticus idriacus (Roewer, 1931), and T. morisii (Brignoli, 1975) (Pantini and Isaia, 2019). The Italian Domitius species are all considered troglobionts (Mammola and Isaia, 2017) showing extreme adaptations to the subterranean environment (e.g. reduction of eyes, depigmentation, and elongation of legs). Such spiders are characterized by a limited distribution, and are endemic to a small number of caves in Northern (D. menozzii, D. speluncarum) or Central (D. sbordonii) Apennines mountains (Brignoli, 1979, Ribera, 2018). Initially, the taxonomy and geographic range of $D$. menozzii and $D$. speluncarum were uncertain: the two species were often mistaken for each other, or considered as subspecies or a synonymy of K. eremita (see Brignoli, 1971 202-205, in Italian). Dresco (1966) and Brignoli (1971) revised the taxonomy of $D$. menozzii and $D$. speluncarum, pinpointing their differences. Nevertheless, there is still occasional confusion regarding their taxonomic status: for example, $D$. speluncarum is sometimes wrongly attributed to the Dinaric Alps (Pavlek and Ribera, 2017).

Individuals of $D$. speluncarum and $D$. menozzii were found by the author while collecting in caves in Liguria and Toscana Regions (Italy). Specimens from one cave appeared to show distinct morphological differences. A more detailed examination of genitalia revealed that those specimens represented a new species. In this paper, the new species is described. The morphological differences between the Italian Domitius species are explored in detail, and the precise geographical distribution of the genus in the Italian peninsula is illustrated. To better establish the systematic position of the species, a phylogenetic tree of the genus Domitius, in relation with the other main European nesticid genera, is carried out.

\section{MATERIAL AND METHODS}

\section{Taxonomy}

Fresh specimens were hand-collected in caves and fixed in $96 \%$ ethanol for molecular and morphological analysis. Photographs and measurements of the samples were taken at the Museo Civico di Storia Naturale of Verona, Italy, using a Leica DFC450 digital camera mounted on a Leica M165C steremicroscope. A Leiz Diaplan microscope was used to photograph the vulvae. Images were subsequently combined using Helicon Focus 6 image stacking software. The left palps of males were photographed. Epigynes were dissected using a sharp needle and boiled for a few minutes in a $20 \%$ $\mathrm{KOH}$ solution to show the vulval internal structures. Leg measurements are given as following: total length (femur, patella,

${ }_{1}^{1}$ Systematic Zoology Laboratory, Department of Biological Sciences, Tokyo Metropolitan University 1-1 Minami-Osawa, Hachioji-shi, Tokyo, 192-0397, Japan. ballarin.francesco@gmail.com.

2 Department of Zoology, Museo Civico di Storia Naturale of Verona, Lungadige Porta Vittoria, 9 I-37129 Verona, Italy. 
tibia, metatarsus, tarsus). All measurements are reported in millimeters. Unless otherwise specified, type descriptions are based on wet specimens in ethanol. Specimens used in this study are stored in the collections of the Museo Civico di Storia Naturale of Verona (MSNV) and Museo Civico di Storia Naturale "E. Caffi" of Bergamo (MSNB). The following abbreviations are used in the text and figures: $A M=$ anterior median eyes; $A L=$ anterior lateral eyes; $C=$ conductor complex; $\mathrm{Cd}=$ copulatory duct; $\mathrm{Co}=$ copulatory opening; Da 1-3 = dorsal apophyses of the paracymbium; $\mathrm{Di}=$ distal apophysis of the paracymbium; $\mathrm{E}=$ embolus; $\mathrm{Id}=$ insemination duct; $\mathrm{Ma}=$ median apophysis; $\mathrm{Ms}=$ median septum; $\mathrm{P}=$ paracymbium; $\mathrm{Pc} 1-3=$ processes of the conductor complex; $\mathrm{PM}=$ posterior median eyes; $\mathrm{PL}=$ posterior lateral eyes; $\mathrm{S}=$ spermatheca; $\mathrm{St}=$ subtegulum; $\mathrm{T}=$ tegulum; $\mathrm{Va}=$ ventral apophysis of the paracymbium; $\mathrm{Vp}=$ vulval pocket.

\section{Breeding}

To increase the available number of adult specimens and to obtain information about the life-cycle of the species for further research, juveniles of $D$. culsu sp. nov. at different growth stages were collected and raised in captivity in the basement of the Museo Civico di Storia Naturale of Verona. Each specimen was kept in a box (size $10 \times 5 \times 3 \mathrm{~cm}$ ) made of plaster, with a glass lid and a layer of cave mud on the bottom. All boxes were placed in a large plastic tray with a transparent plexiglass lid and a layer of plaster on the bottom. To maintain the correct degree of humidity, the bottom of the tray was moistened with water every two weeks. Specimens were frequently checked and fed with fruit flies or mosquitoes approximately once or twice per month.

\section{Molecular Analysis}

Sequences of Domitius species and other European nesticids were obtained from freshly collected specimens or acquired from the GenBank online database (GenBank, 2018). Since preliminary phylogenetic analysis of the family suggests Gaucelmus is a sister clade to all Nesticidae sensu stricto (Ballarin and Li, in prep.), Gaucelmus augustinus Keyserling, 1884 from North America was set as an outgroup to root the tree. Extraction of DNA, and PCR amplification, were performed in the Institute of Zoology, Chinese Academy of Sciences, Beijing, China (IZCAS). All fresh specimens used for the molecular analysis were identified at species level using morphology, before storing at $-20^{\circ} \mathrm{C}$ at IZCAS. For each species, total genomic DNA was extracted from two legs of an adult specimen using a TIANamp Genomic DNA Kit (TIANGEN) under the standard protocol suggested by the manufacturer. The PCR amplifications were performed with an Eppendorf thermal cycler (Hamburg, Germany) using a final volume of 25 $\mu \mathrm{L}$. Purified PCR products were sequenced in both directions using an ABI 377 automatic sequencer (Applied Biosystems, Foster City, CA, USA) with a BigDye terminator cycle sequencing ready reaction kit. Partial fragments of the mitochondrial genes cytochrome c oxidase subunit I (COI) and 16S rRNA (16S) and the nuclear gene Histone $\mathrm{H} 3(\mathrm{H} 3)$ were selectively amplified following protocols and primers as indicated in Ballarin and $\mathrm{Li}$ (2018). Raw sequences were aligned using the online version of MAFFT v.7.0 (Katoh and Standley, 2013) under the algorithms G-INS-i for COI and H3 and Q-INS-i for 16S. Aligned sequences were subsequently visually inspected for mismatching and edited with BioEdit v.7.2.5 (Hall, 1999). A Maximum Likelihood (ML) analysis under a GTRGAMMA nucleotide substitution model was performed using the online version of RAxML v.8.2.0 (Stamatakis, 2014) on CIPRES Science Gateway V. 3.3 (Miller et al. 2010, available at: https://www.phylo.org/). One thousand replicates of rapid bootstrap were performed twice, using an individual gene partition scheme. Uncorrected pairwise-distance genetic divergences between the species was performed using MEGA v.7.0.14 (Tamura et al., 2013). The list of species used in the analysis and related GenBank accession numbers of the sequences are reported in Table 1.

\section{RESULTS}

\section{Taxonomy}

Class Arachnida Cuvier, 1812

Order Araneae Clerck, 1757

Family Nesticidae Simon, 1894

Genus Domitius Ribera, 2018

Domitius culsu Ballarin sp. nov.

Figures $1 \mathrm{~A}-\mathrm{G}, 2 \mathrm{~A}-\mathrm{E}, 3 \mathrm{~A}-\mathrm{D}$.

Nesticus speluncarum Brignoli, 1979: 214 (misidentification)

Type material. Holotype $\widehat{\delta}$. ITALY, Toscana: Garfagnana area, Lucca Province, Coreglia Antelminelli Municipality, Tana delle Fate di Coreglia Antelminelli cave, 141/T/LU, $260 \mathrm{~m}$ a.s.I., $44.046336^{\circ} \mathrm{N} 10.523525^{\circ} \mathrm{E}, 21 . \mathrm{VIII} .2018$, leg. F. Ballarin and D. Avesani (MSNV). Paratypes. Same locality as the holotype, 19, 04.IX.1967, leg. A. Vigna Taglianti (MSNV) (Brignoli 1979, sub Nesticus speluncarum); 1울. 15.VIII.2015, leg. F. Ballarin and M. Gaiga (MSNV); 4우으, 24.VI.2017, (3우 collected as juveniles and raised in captivity, adults: 20.VIII.2017, 15.IX.2017 and 28.VI.2018 respectively), leg. F. Ballarin and R. Ballarin (MSNV); 4ㅇ, 21.VIII.2018, leg. F. Ballarin and D. Avesani (MSNV, MSNB). 
Table 1. Species, GenBank accession numbers, and locality of the specimens used in the phylogenetic analysis.

\begin{tabular}{|c|c|c|c|c|c|}
\hline Species & Code & COI & $16 S$ & H3 & Locality \\
\hline Domitius baeticus & Dbae & MF693114 & MF693118 & MF693106 & Cueva del Castillo. Siles, Jaén. Spain \\
\hline Domitius luquei & Dluq & MF693112 & EU746439 & MF693104 & $\begin{array}{l}\text { Cueva de la Picona, San Pedro de Carmona, Cabuérniga, } \\
\text { Cantabria, Spain }\end{array}$ \\
\hline Domitius lusitanicus & Dlus & MF693113 & EU746429 & MF693105 & Algar de Marradinhas II, Concelho de Alcanena, Portugal \\
\hline Domitius menozzii & D213 & MK860151 & MK860133a & MK860142a & Tanna da Suja, Prati di Bavari, Liguria, Italy \\
\hline Domitius culsu sp. nov. & D555 & MK860152a & MK860134 & MK860143a & $\begin{array}{l}\text { Tana delle Fate di Coreglia Antelminelli, Coreglia } \\
\text { Antelminelli, Toscana, Italy }\end{array}$ \\
\hline Domitius sbordonii & Dsbo & MF693110 & MF693116 & MF693102 & Tana degli orchetti, Supino, Lazio, Italy \\
\hline Domitius speluncarum & D557 & MK860153a & MK860135a & MK860144 ${ }^{\mathrm{a}}$ & Tana di Magnano, Canigiano, Lucca, Toscana, Italy \\
\hline Nesticus cellulanus & N214 & MK860154 & MK860136 & MK860145 & Cave of Koufovouno, Didimoticho, Thrace, Greece \\
\hline Kryptonesticus dimensis & K566 & MK860155a & MK860137a & MK860146a & Dim cave, Antalya, Turkey \\
\hline Kryptonesticus eremita & K211 & MK860156 & MK860138 & MK860147a & Grotta di Ponte Subiolo, Mori, Veneto, Italy \\
\hline Carpathonesticus fodinarum & C162 & MK860157 & MK860139a & MK860148a & Small cave along the river, Sighistel, Bihor, Romania \\
\hline Carpathonesitcus lotriensis & C166 & MK860158 & MK860140a & MK860149a & $\begin{array}{l}\text { Humid and shadowed cliff near Lazaret village, Sibiu, } \\
\text { Romania }\end{array}$ \\
\hline Typhlonesticus obcaecatus & Tobc & KF939309 & EU746437 & MF693109 & Cueva del Molino de Aso, Boltana, Huesca, Spain \\
\hline Typhlonesticus idriacus & T167 & MG201050 & MG200521 & MG201227 & Grotta Pre Oreak, Nimis, Udine, Friuli Venezia Giulia, Italy \\
\hline Typhlonesticus morisii & Tmor & KF939311 & KF939308 & $\cdots$ & Sotterranei del Forte di Vernante, Vernante, Cuneo, Italy \\
\hline Gaucelmus augustinus & G601 & MK860159a & MK860141 & MK860150 & Climax cave, Bainbridge, Georgia, USA \\
\hline
\end{tabular}

a New Sequences.

Examined comparative material. Domitius speluncarum (Pavesi, 1873): ITALY: Liguria: 10ิ, 1, (topotypes), La Spezia Province, Grotta Bocca Lupara cave, 74/Li/SP, 120m a.s.I., 05.III.1969, leg. P.M. Brignoli (MSNV) (Brignoli, 1971); Toscana: 1이 Lucca Province, Garfagnana area, Villa Collemandina Municipality, Canigiano village, Tana di Magnano cave, 162/T/LU, 653m a.s.I., 44.177285 $\mathrm{N}, 10.38803^{\circ} \mathrm{E}, 03 . X I .1967$, leg. A. Vigna Taglianti (MSNV) (Brignoli,

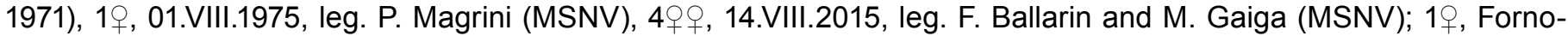
volasco (not reported in the label but very likely from Grotta del Vento cave), 700m a.s.l., 16.VI.1970, leg. O. Osella (MSNV) (Brignoli, 1971); 1, Grotta del Buggine cave, 166/T/Lu, 315m a.s.l., 07.X.1967, leg. G. Castellini (MSNV) (Brignoli, 1971); 1오․ Massa-Carrara, Buca della Freddana cave, 230/T/Ms, 550m a.s.l., 05.VI.1977, leg. C. Bonzano (MSNV) (Brignoli, 1985); 1오․ Buca del Bacile cave, 226/T/Ms, 10.III.1975, leg. unknown (MSNV) (Brignoli, 1985).

Domitius menozzii (di Caporiacco, 1934): ITALY, Liguria, $1 \hat{\delta}, 4+q$, north-east of Genova town, Tanna da Vulpe cave, 264/Li/GE, 23.XI.1969, leg. A. Vigna Taglianti (MSNV) (Brignoli, 1971); 2ððð, 2우, Creto, Tanna de Fate cave, 17/ Li/GE, 30.X.1971, leg. G. Gardini (MSNV); 2 o (topotypes), Prati di Bavari locality, Tanna da Suja cave, 5/Li/GE, 582m a.s.I., $44.422894^{\circ} \mathrm{N}, 09.035239^{\circ} \mathrm{E}, 30 . \mathrm{V} .2013$, leg. F. Ballarin, A. Trotta, G. Gardini, and S. Zoia.

Domitius sbordonii (Brignoli, 1979): ITALY, Lazio, $1{ }^{\widehat{A}}$ (holotype), Frosinone Province, Supino, Valle Serena, Grotta della Croce cave, 01.IX.1977 leg. V. Sbordoni (MSNV) (Brignoli, 1979); 1 ㅇ (paratype), 08.Il.1976, leg. V. Sbordoni (MSNV) (Brignoli, 1979).

Kryptonesticus eremita (Simon, 1880): ITALY, Liguria: $2 \hat{\jmath} \widehat{\jmath}$ (sub. Nesticus menozzii), Creto, Tanna de Fate cave, 17/Li/GE, 30.X.1971, leg. G. Gardini (MSNV); Emilia-Romagna: $2+q$ Ravenna Province, Riolo Terme, Borgo Rivola, Grotta del Re Tiberio cave, 36/Er/RE. 19.Il.1951, Leg. Denis (MSNV) (Zangheri, 1966, sub. Nesticus speluncarum); Toscana: 1 q Garfagnana area, Lucca Province, Coreglia Antelminelli Municipality, Tana delle Fate di Coreglia Antelminelli cave, $141 / \mathrm{T} / \mathrm{LU}, 260 \mathrm{~m}$ a.s.I., $44.046336^{\circ} \mathrm{N}, 10.523525^{\circ} \mathrm{E}, 15 . \mathrm{VIII} .2015$, leg. F. Ballarin and M. Gaiga (MSNV); 3우, 24.VI.2017, Leg. F. Ballarin and R. Ballarin (MSNV-MSNVRAr/m 0007); 1, 21.VIII.2018, leg. F. Ballarin and D. Avesani (MSNV); Campania: 1, Avellino Province, Bagnoli Irpino, Mt. Piacentini, Grotta Giovannino cave, 16.VI.1956, leg. S.Ruffo (MSNV) (Kritscher, 1958, sub. Nesticus speluncarum).

\section{Etymology}

The name of the new species is derived from the Etruscan goddess Culsu who, according to the Etruscan mythology, ruled the cave-like entrance of the underworld. Noun in apposition. 

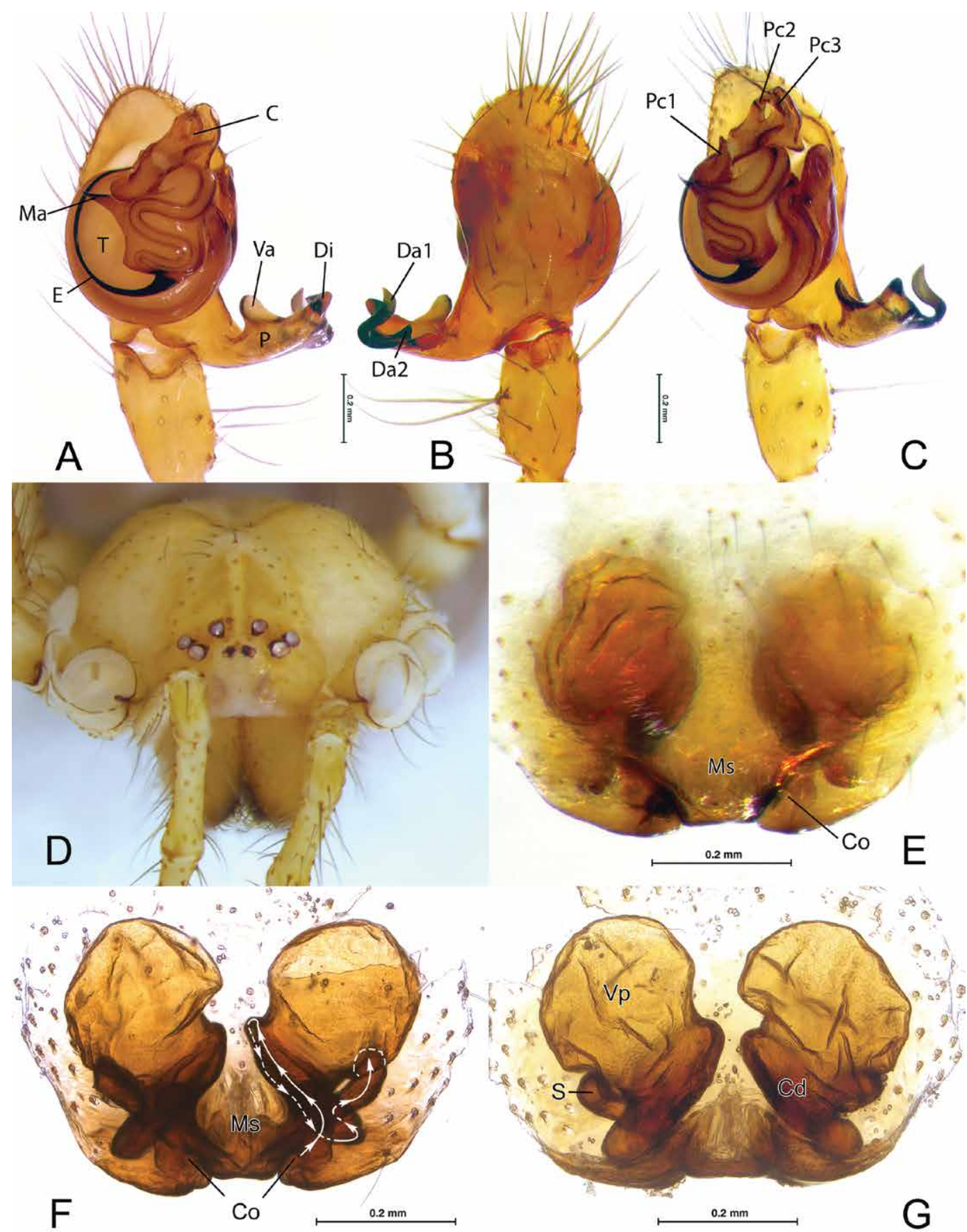

Figure 1. Nesticus culsu sp. nov. Male palp: A. ventral view; B. dorsal view; C. retrolateral view; D. female, cephalic region showing the eye pattern; E. epigyne, ventral view; F. epigyne after clearing, ventral view, the schematic course of internal ducts is outlined with a white line; G. vulva after clearing, dorsal view.

\section{Diagnosis}

Species closely related to $D$. speluncarum and D. menozzii. Males of $D$. culsu sp. nov. can be separated from males of all other Italian species of the genus Domitius by the different shape of the apophyses of the paracymbium (Figs. $1 \mathrm{~A}-\mathrm{C}$, $2 \mathrm{~B}, \mathrm{C}$ vs. Fig. $4 \mathrm{~A}-\mathrm{I})$. $D$. culsu sp. nov shows a robust, S-shaped dorsal apophysis 1 in contrast with a large, flat and axelike Da 1 in $D$. speluncarum (Figs. 1A-C, 2B, C vs. Fig. $4 A-C)$; a short and stumpy $D a 1$ in $D$. menozzii (Figs. 1A-C, 2B, C vs. Fig. 4D-F) or a long and thread-like $\mathrm{Da} 1$ in D. sbordonii (Figs. 1A-C, 2B, C vs. Fig. 4G-I). Additionally, males of $D$. culsu sp. nov. have a well-developed, triangular median apophysis, absent in males of the other three species (Figs. 1A, 2A vs. Fig. 4A, D, G).

Female $D$. culsu sp. nov. can be easily distinguished from female $D$. speluncarum by the narrower, trapezoid-shaped median septum with slanting edges, in contrast with the larger, lobate Ms with rounded edges in $D$. speluncarum (Figs. 1E, 2D vs. Fig. 5A). Female $D$. culsu sp. nov. are separated from female $D$. morisii by the absence of a bulge on the Ms (clearly visible in D. morisii, Figs. 1E, 2D vs. Fig. 5C). Additionally, they can be distinguished by the different shape of copulatory ducts when the vulva is observed dorsally: with a rather uniform diameter in $D$. culsu sp. nov. and bearing a large, flattened middle trait in $D$. morisii (Figs. 1G, 2E vs. Fig. 5D). Female $D$. culsu sp. nov. are easily separated from those of $D$. sbordonii by the trapezoid-shaped Ms with slanting edges, in contrast with the squared Ms with vertical edges in $D$. sbordonii (Figs. 1E, 2D vs. Fig. 5E). They can further be distinguished by the different position of spermathecae, located in the lower half of the vulva and below the vulval pockets in $D$. culsu sp. nov., in contrast with $S$ located in the upper half of vulva and above Vp in $D$. sbordonii (Figs. 1G, 2E vs. Fig. 5F). 


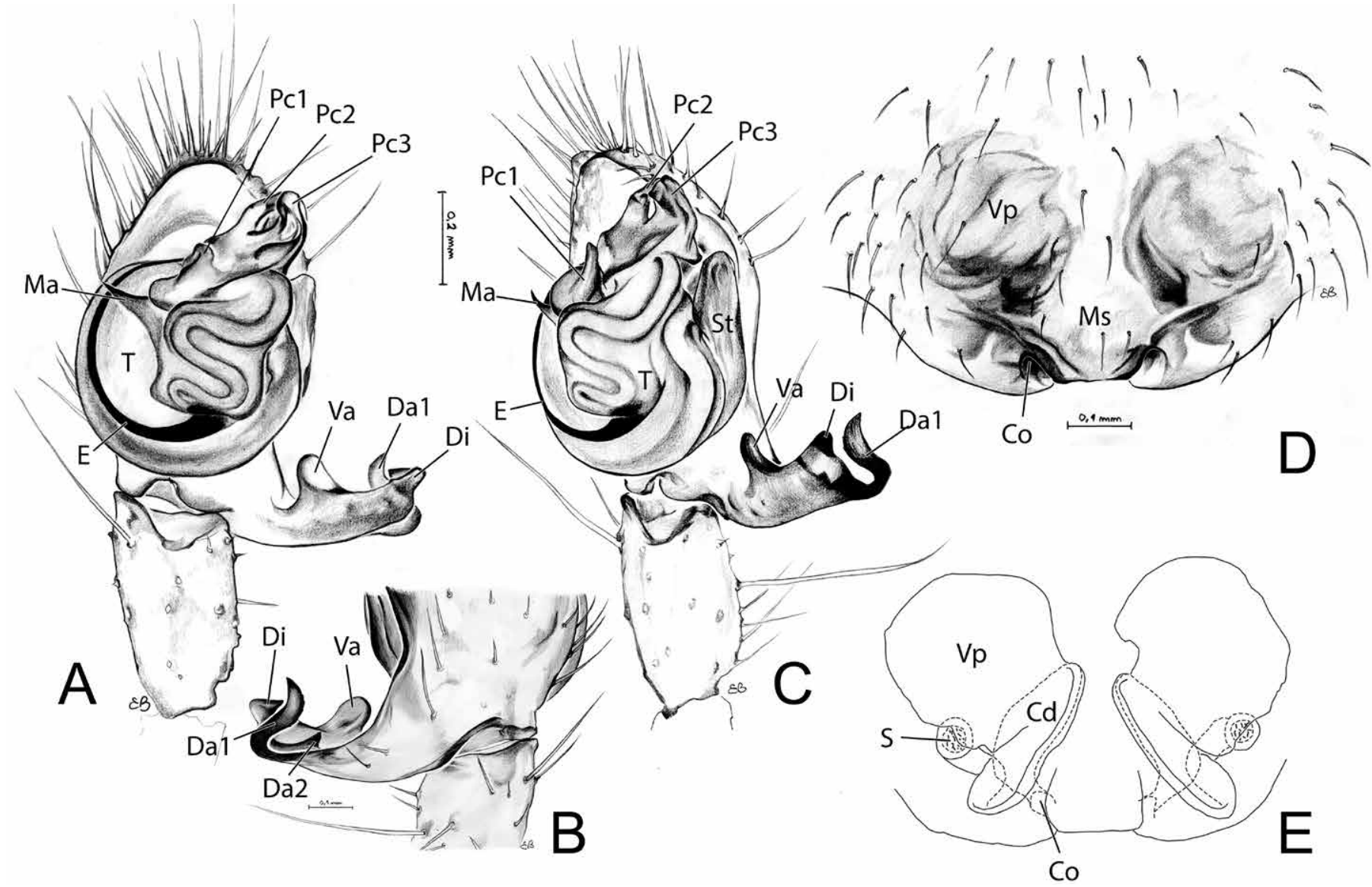

Figure 2. Genitalia of Nesticus culsu sp. nov. Male palp: A. ventral view; B. dorsal view of the paracymbium; C. retrolateral view; D. female epigyne, ventral view; E vulva, dorsal view.

Description. Male (holotype). Total length 4.19. Carapace: 1.81 long, 1.56 wide.

Habitus as in Fig. 3A. Carapace uniformly pale yellow with some sparse setae (more reddish while alive, see Fig. $3 A$ ). Cephalic region not clearly differentiated from the rest of carapace. Eyes reduced, AM missing, reduced to black maculae. Eye diameters: AM -, AL 0.079, PM 0.080, and PL 0.078. Thoracic grooves and fovea distinct. Mouthparts and sternum uniformly colored as the carapace. Promargin of chelicera with three teeth approximately of the same size, retromargin with several small denticles. Legs uniformly light yellowish. Legs measurements as follows: I 17.40 (4.89, 0.90, 4.78, 4.90, 1.93), II 14.03 (3.92, 0.80, 3.67, 3.76, 1.88), III 10.35 (3.19, 0.69, 2.53, 2.79, 1.15), IV 13.47 (4.34, 0.84, $3.53,3.49,1.27)$. Leg formula: I, II, IV, III. Opisthosoma gray-yellowish colored (lighter than carapace while alive, see Fig. 3A), covered with long hairs.

Palp as in Figs. 1A-C, 2A-C. Cymbium oval, covered with short, sparse setae, with a tuft of longer hairs in the prolateral distal area near the tip. Embolus filamentous, slender in the terminal part. Conductor complex with three distinct processes: Cp 1-3. Cp 1 stocky and roughly triangularly shaped, $\mathrm{Cp} 2$ and $\mathrm{Cp} 3$ located at the distal part of the bulb and diagonally protruding (approx. 2 o'clock seeing the left palp ventrally), their tips curved towards each other (Figs. 1A, C, 2A, C). Median apophysis well-developed, shaped as a long, sharp triangle, heading prolaterally (Figs. 1A, 2A). Paracymbium large with well-developed, sclerotized dorsal, distal and ventral processes. Two dorsal apophyses, Da 1-2: Da 1 robust and long, ending sharply, S-shaped when the palp is observed dorsally, Da 2 stocky, triangularly-shaped. Distal apophysis triangularly shaped. Ventral apophysis lobate, dorso-ventrally flattened and heading toward the cymbium (Figs. 1A-C, 2A-C).

Female (based on 4 paratypes). Total length 3.65-5.27. Carapace: 1.71-1.98 long, 1.54-1.64 wide.

Habitus as in Fig. 3B, C. Carapace uniformly yellowish with some sparse setae (often more reddish while alive, see Fig. 3B). Cephalic region not clearly differentiated from the rest of the prosoma. Eyes reduced, AM strongly reduced and barely visible, reduced to small, dark maculae in some specimens. Eye diameters: AM (when present): 0.032, AL: 0.087, PM: 0.078 , and PL: 0.77 . Thoracic grooves and fovea distinct. Mouthparts and sternum uniformly colored as in the carapace. Teeth of chelicera as in the male. Legs uniformly light yellowish. Leg measurements as follows: I 17.07 (4.38, 1.01, 4.95, 4.90, 1.83), II 13.69 (4.04, 0.92, 3.57, 3.64, 1.52), III 10.46 (3.43, 0.80, 2.50, 2.56, 1.17), IV 13.89 (4.64, 0.92, 3.59, 3.41, 

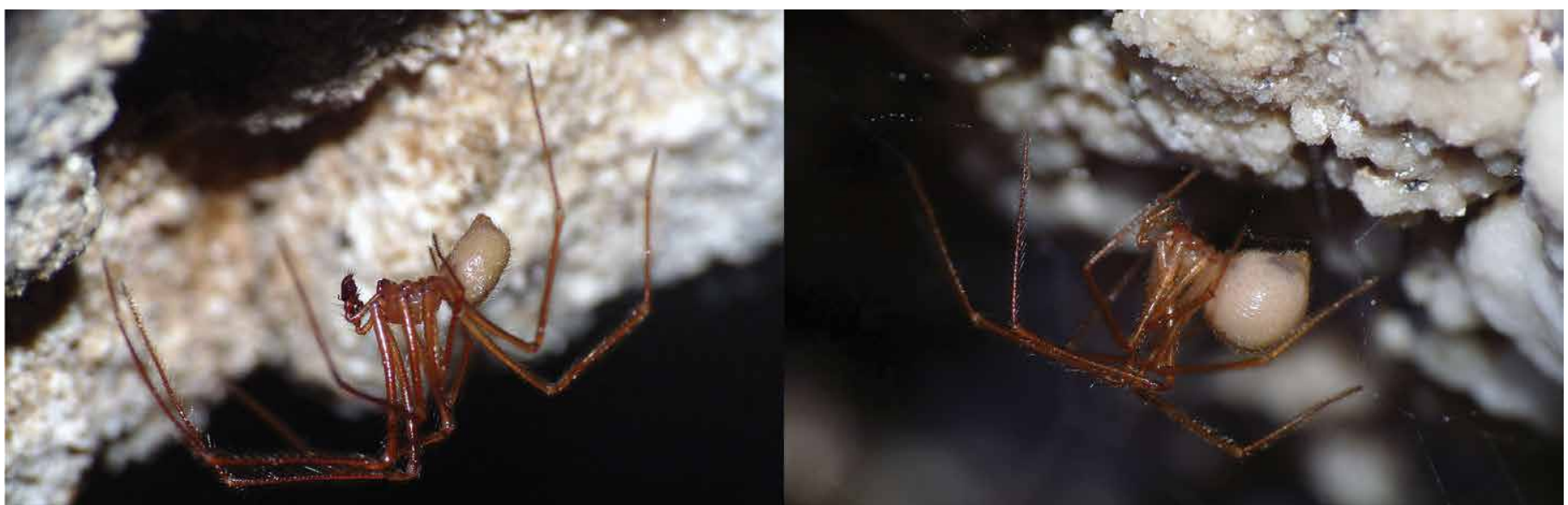

A

$\mathrm{B}$
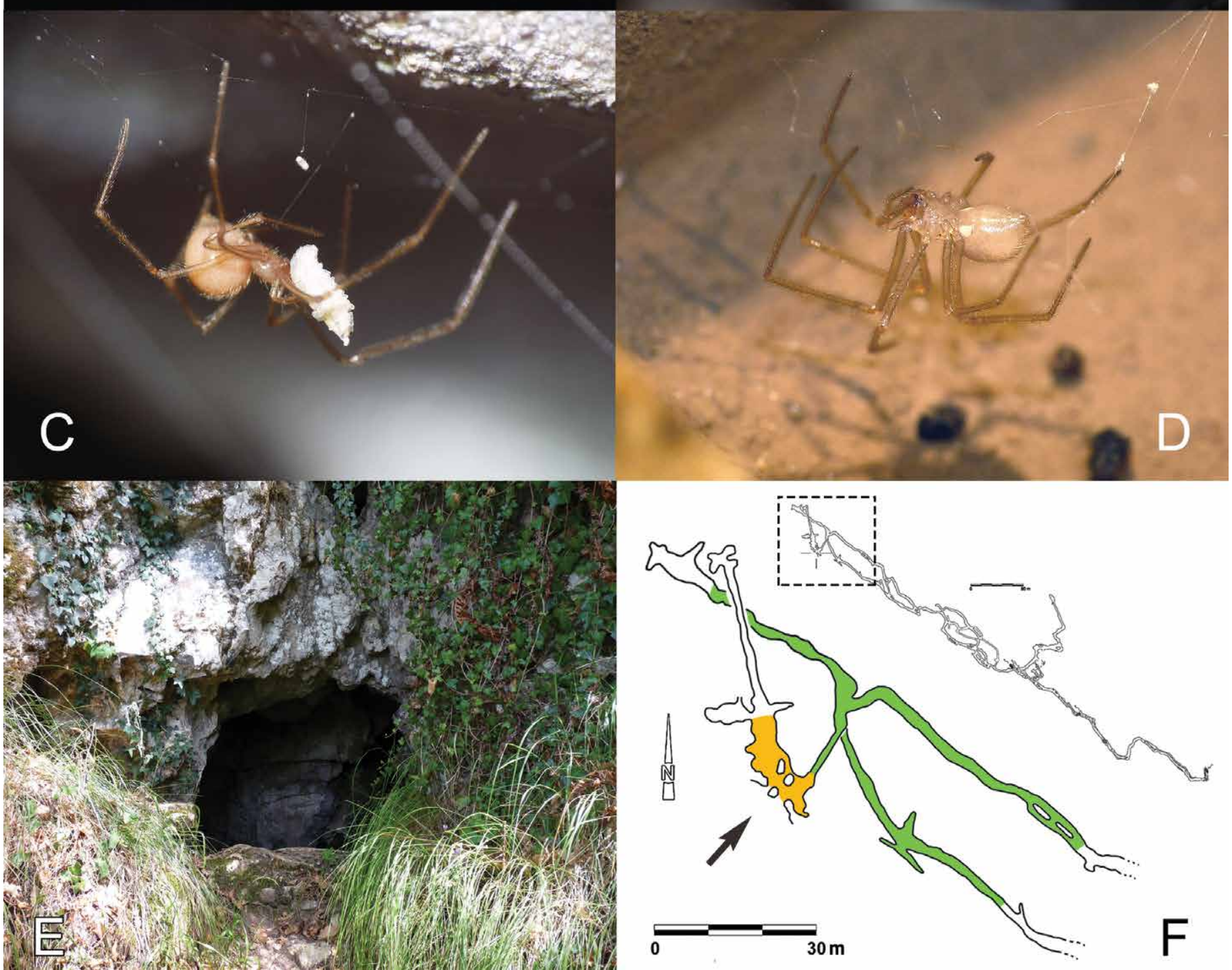

Figure 3. Habitus and type locality of Domitius culsu sp. nov. A. Habitus of male; B. habitus of female; C. female with prey; D. juvenile in captivity; E. entrance of Tana delle Fate di Coreglia Antelminelli cave; F. map of the cave and detail of the entrance, showing the spatial distribution of the two co-existing nesticid species living inside: green $=D$. culsu sp. nov., orange $=$ Kryptonesticus eremita, arrow $=$ entrance of the cave. 


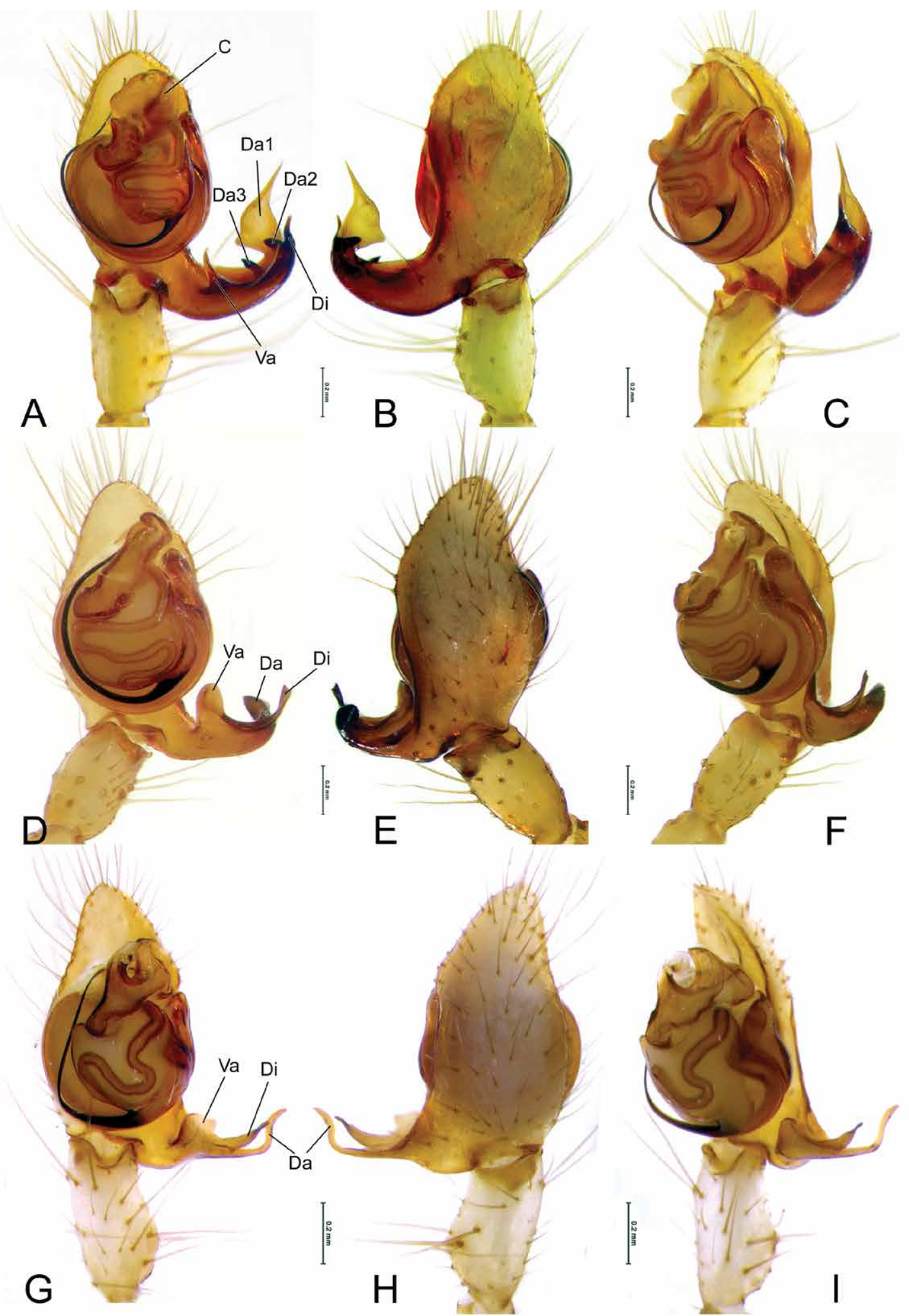

Figure 4. Male palps of the Italian Domitius species for comparison. D. speluncarum male palp: A. ventral view; B. dorsal view; C. retrolateral view; $D$. menozzii male palp: D. ventral view; E. dorsal view; F. retrolateral view; $D$. sbordonii male palp: G. ventral view; H. dorsal view; I. retrolateral view.

nines. Known only from the type locality; Tana delle Fate di Coreglia Antelminelli cave (Fig. 6).
1.33). Leg formula: I, IV, II, III. Opisthosoma yellowish-gray (often lighter colored than carapace while alive, see Fig. 3B), covered with long hairs.

Epigyne as in Figs. 1E, F, 2D, E. Median septum short, not protruding, shaped as an inverted trapezoid with a narrower base. Vulval pockets and copulatory ducts externally visible by transparence trough the tegument. Copulatory openings at the lower, lateral side of median septum. Vulva as in Figs. 1G, 2E. Spermathecae small and round, located in the lower-half of the vulva, below vulval pockets and being partially covered by them. Vulval pockets wide and rounded, sac-shaped, located above spermathecae. Copulatory ducts with a wider diameter in the ventral trait and narrower in the dorsal trait, rolling up around the lower part of vulval pockets and reaching spermathecae with some turns (Figs. 1F, 2E). Insemination ducts beginning from the lower part of spermathecae and following the same course of copulatory ducts.

\section{Distribution}

Italy, endemic to the northern Apen- 


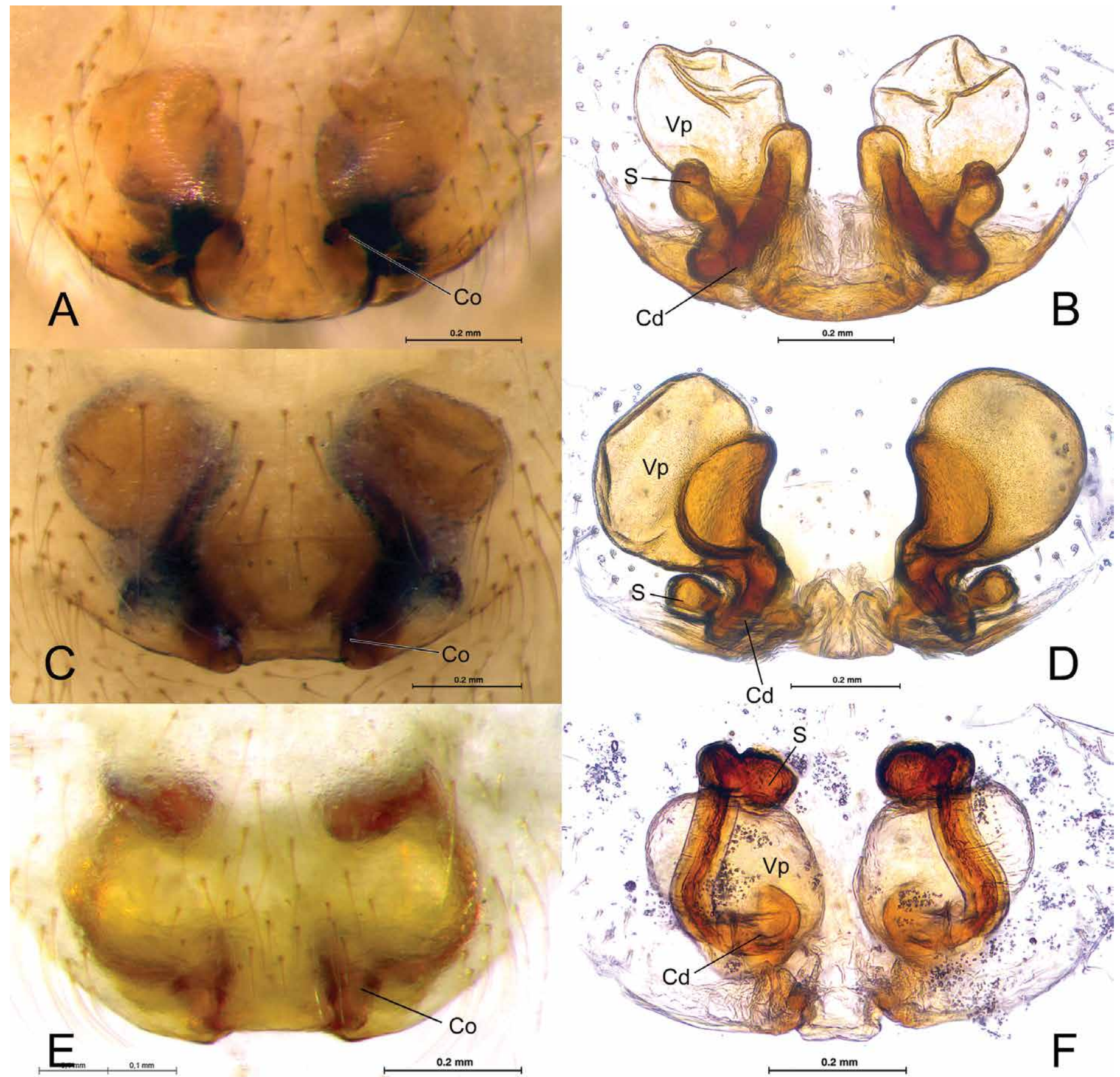

Figure 5. Female epigyne of the Italian Domitius species for comparison. D. speluncarum: A. epigyne, ventral view; B. vulva, dorsal view; D. menozzii: C. epigyne, ventral view; D. vulva, dorsal view; $D$. sbordonii: E. epigyne, ventral view; F. vulva.

\section{Biospeleological and ecological notes}

The entrance of Tana delle Fate di Coreglia Antelminelli cave (Italian National Caves Registry number: 141/T/LU; Fig. 3E) opens in the left bank of the narrow valley of Segone Creek in the Province of Lucca (Toscana region) at an elevation of $260 \mathrm{~m}$ a.s.l. The cave occurs in the limestone of the Maiolica formation (lower Tithonian-lower Aptian, $\sim 150-120 \mathrm{Ma}$ ), which is particularly rich in flint nodules. After an initial steep slope (approximately $10 \mathrm{~m}$ deep), the cave continues with a long and sub-horizontal spatial development and a general NW-SE orientation (Fig. 3F). It branches with several, sub-circular tunnels as a result of ancient groundwater flows. The cave has an estimated total extension of $1100 \mathrm{~m}$, although the deeper segments are still unexplored, as they are either filled with water or ending with sumps. The inner section is generally humid, with mud often covering the bottoms of the tunnels. The cave hosts a rich subterranean fauna including some endemic or locally protected species, e.g. the carnivorous land snail Oxychilus sp. (Gastropoda, Oxychilidae), the cave cricket Dolichopoda laetitiae Minozzi, 1920 (Orthoptera, Rhaphidophoridae), the 


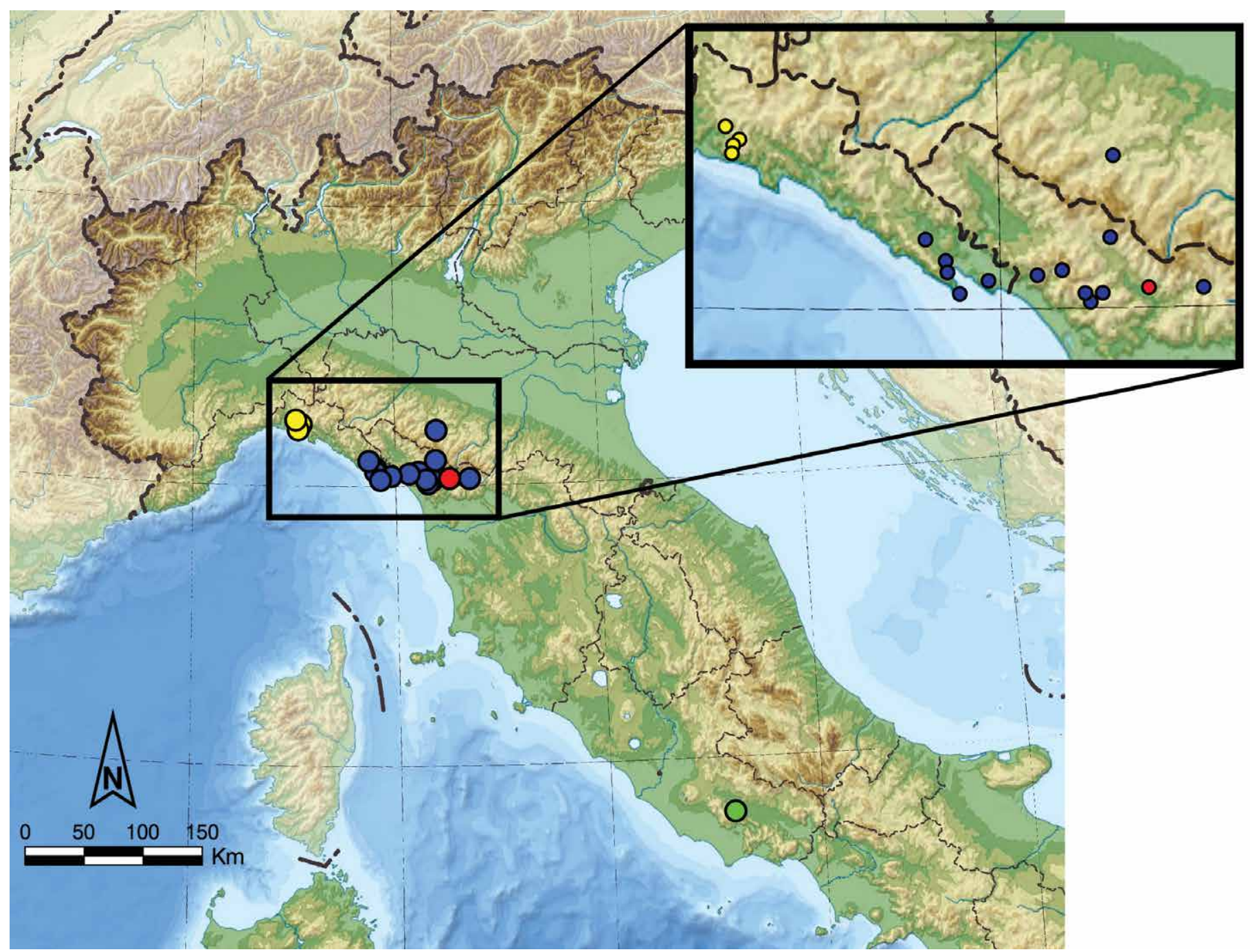

Figure 6. Distribution of the genus Domitius in Italy. Yellow dots $=D$. menozzii, blue dots $=D$. speluncarum; red dot $=D$. culsu sp. nov.; green dot $=D$. sbordonii.

blind subterranean beetle Duvalius apuanus lanzai Straneo, 1943 (Coleoptera, Trechinae), the Italian cave salamander Speleomantes italicus (Dunn, 1923) (Amphibia, Plethodontidae), and three species of bats: the greater horseshoe bat Rhinolophus ferrumequinum (Schreber, 1774), the lesser horseshoe bat Rhinolophus hipposideros (Bechstein, 1800) (Chiroptera, Rhinolophidae), and the common bent-wing bat Miniopterus schreibersii (Kuhl, 1817) (Chiroptera, Miniopteridae). Other animals known from the cave from the literature (Lanza, 1961) or directly observed by the author include: Octodrilus complanatus (Dugès, 1828), O. hemiandrus (Cognetti, 1901), O. transpadanus (Rosa, 1884), and Aporrectodea rosea (Savigny, 1826) (Anellida, Lumbricidae); Chaetophiloscia cellaria (Dollfus, 1884) (Isopoda, Philosciidae), Androniscus dentiger Verhoeff, 1908, and Spelaeonethes mancinii (Brian, 1913) (Isopoda, Trichoniscidae); Euscorpius carpathicus (Linnaeus, 1767) (Scorpiones, Euscorpiidae); Trogulus sp. (Opiliones, Trogulidae), Ischyropsalis adamii Canestrini, 1873 (Opiliones, Ischyropsalididae); Lithobius tylopus Latzel, 1882 (Chilopoda, Lithobiidae), Gryllomorpha dalmatina (Ocskay, 1832) (Orthoptera, Gryllidae), Hypaena sp. (Lepidoptera, Noctuidae), Stenophylax permistus McLachlan, 1895 (Tricoptera, Limnephilidae), and a large population of limoniid crane flies (Diptera, Limoniidae). Near the entrance and in the early section of the cave, numerous spiders were also observed: Amaurobius ferox (Walckenaer, 1830), A. pesarinii Ballarin and Pantini, 2017 (Amaurobiidae), Kryptonesticus eremita (Simon, 1880) (Nesticidae), Meta menardi (Latreille, 1804), Metellina merianae (Scopoli, 1763) (Tetragnathidae), Pholcus phalangioides (Fuesslin, 1775) (Pholcidae), and Tegenaria sp. (Agelenidae). The new species was found in the initial segments of the cave, but at some distance from the entrance (Fig. 3F). During summer, when the cave was visited, adults, subadults, and juveniles of $D$. culsu sp. nov. were observed together, with a substantially higher number of adults and subadults during the month of August. Most of the juveniles collected in the cave and bred in captivity became adults after 2-3 months of captivity, while it took approximately one year for the youngest specimens to reach sexual maturity. 


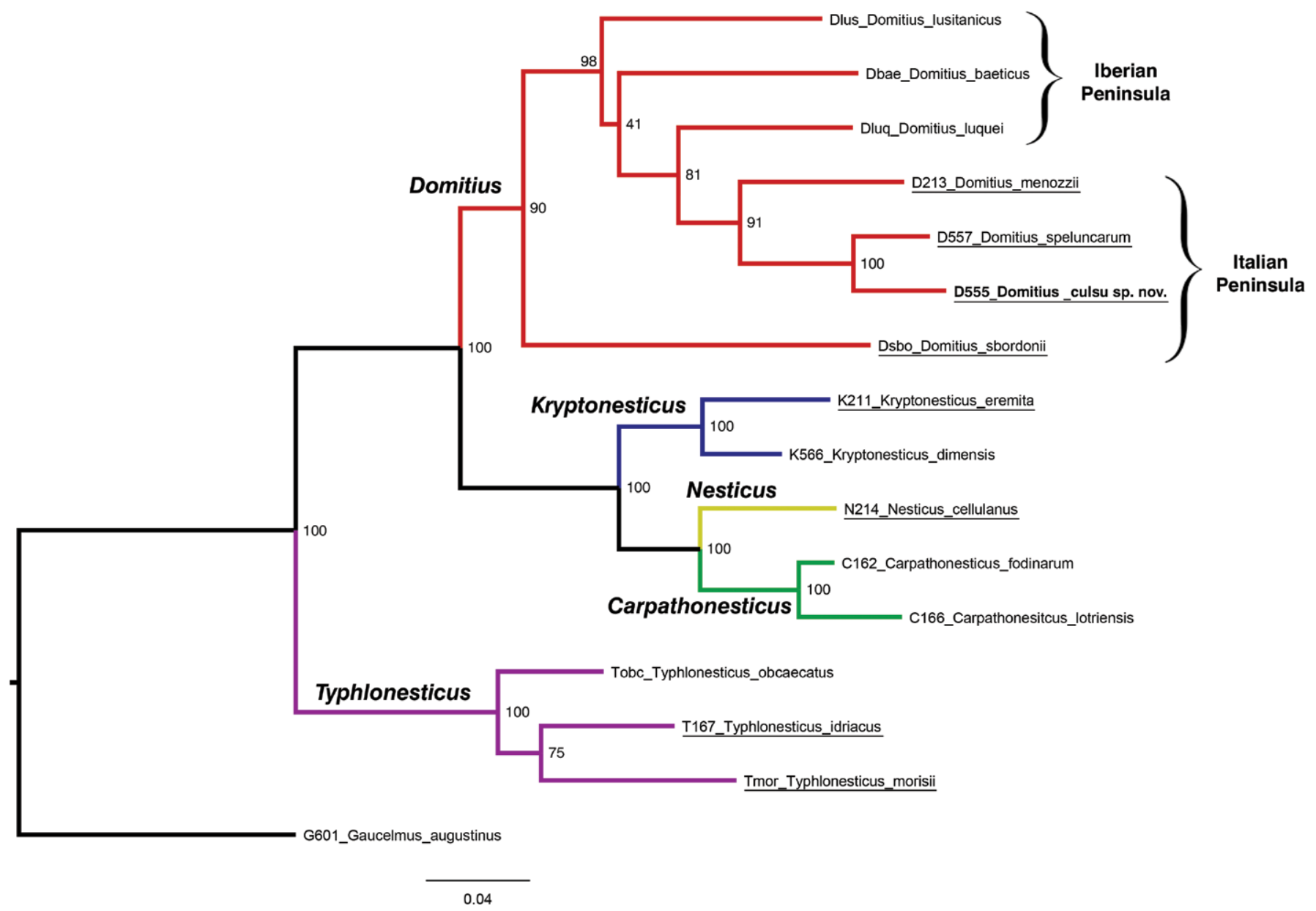

Figure 7. Phylogenetic tree of the main European nesticid genera inferred using ML in RAxML. Different colored branches reflect different genera: violet = Typhlonesticus, green = Carpathonesticus, yellow = Nesticus, blue = Kryptonesticus, red = Domitius. The newly-described species is highlighted in bold. Species distributed in Italy are underlined. Code before each species refers to the origin of the data, see Table 1. Branch lengths are scaled in relation to the number of substitutions per site; numbers at nodes denote bootstrap support according to ML.

Two different species of nesticid spiders, $K$. eremita and $D$. culsu sp. nov., were collected together in the Tana delle Fate di Coreglia Antelminelli cave. These species cover a different spatial distribution within the cave (Fig. 3F), coexisting without overlapping despite occupying approximately the same ecological niche. Cohabitant nesticids, in particular involving $D$. menozzii or $D$. speluncarum together with $K$. eremita, have been previously observed in several occasions in Italian caves, and sometimes collected at short distances from each other (Brignoli, 1971). However, no clear species overlap are reported within the same cave. Such distinct spatial partition can be explained by the different grade of adaptation to the hypogean environment showed by these arachnids. In fact, $K$. eremita appears to be a less specialized cave-dweller, lacking extreme morphological adaptations to subterranean life. Therefore, it mostly occurs near the entrance of caves or inside artificial tunnels, including, occasionally, shadowed epigean habitats with constant temperature and high relative humidity (Brignoli, 1971 and personal observations by the author). On the other hand, all Domitius species show a greater degree of adaptation to the subterranean habitat, as suggested by reduction of the eyes and body depigmentation. Such strong adaptation allows Domitius to occupy deeper segments of the caves, thus avoiding direct competition with $K$. eremita.

\section{Conservation Notes}

Since caves are a unique and delicate ecosystem, they are highly susceptible to external disturbance (Culver and Pipan, 2009). Its visible entrance and sub-horizontal extension makes Tana delle Fate di Coreglia Antelminelli cave easily accessible to visitors even with limited experience in speleology, and the cave is often used for training purposes by local speleological clubs. Although not threatened, $D$. culsu sp. nov. should be considered potentially at risk in case of frequent and long-lasting human disturbance due to its strict habitat requirements, its reduced population, and its extremely limited distribution, which appears to be confined to a single cave. Therefore, the new species is a good candidate for species conservation, deserving a place in the list of locally protected species. 


\section{Phylogenetic Analysis}

A total of 16 nesticid species were used in this study, including representatives of the main nesticid genera present in Europe and all the species distributed in the Italian peninsula. Taxon sampling comprised the wide majority of Domitius species. Only D. murgis (Ribera and De Mas, 2003) from Spain was excluded from the analysis due to the absence of available sequences and fresh samples. The final dataset was formed by 1975 pair bases (bp) distributed as; $\mathrm{COI}=$ $1197 \mathrm{bp}, 16 \mathrm{~S}=469 \mathrm{bp}$, and $\mathrm{H} 3=309 \mathrm{bp}$. The resulting phylogenetic tree is illustrated in Figure 7, and the uncorrected pairwise distance between the species is reported in Table 2. The European nesticids cluster into five different clades corresponding to the main genera Carpathonesticus, Domitius, Kryptonesticus, Nesticus, and Typhlonesticus, each of them highly supported (bootstrap support value $=100 \%$ ). Each lineage represents a different and well-defined evolutionary line. These results concur with the outcomes of recent morphological and phylogenetic studies on the family Nesticidae (Pavlek and Ribera, 2017; Ribera, 2018; Ballarin and Li, in prep.), supporting the validity of the newly-established genera. According to these results, Domitius represents the sister lineage of the monophyletic clade formed by the genera Carpathonesticus, Kryptonesticus, and Nesticus, with which it shares a common ancestor. The analysis supports Typhlonesticus as a basal clade within the European Nesticidae, as also suggested by recent molecular studies (Ballarin and Li, 2018; Ribera, 2018). Within Domitius, D. culsu sp. nov. shows a closer affinity with the species from the same geographic area; particularly $D$. speluncarum, but also $D$. menozzi. Its position at the far end of the phylogenetic tree of the genus suggests a more recent origin in comparison with the other congeneric species.

All the Domitius species distributed in the Northern Apennines share a close affinity with species from the Iberian Peninsula. Such close relations also reflected in genital morphology. For instance, all these species share a similar position of spermathecae, located in the lower-half of the vulva, and below the vulval pockets (see Figs. 1G, 5B, D and Figs. 4A-E in Ribera, 2018). On the other hand, D. sbordonii from the Central Apennines appears to be morphologically and genetically separated from all the other species of the genus, including those from Northern Apennines. The difference is highlighted in the peculiar shape of the vulva, being the only Domitius species showing simple-coiled internal ducts and spermathecae located in the upper-half of the vulva, over the vulval pockets (see Fig. 5F vs. Figs. 1G, 5B, D and Figs. 4A-E in Ribera, 2018). Upper-positioned spermathechae are also present in several other European nesticid genera such as Carpathonesticus (sensu stricto), Krypthonesticus, and Nesticus (sensu stricto). Based on these results

Table 2. Uncorrected genetic p-distance of the COI partial sequence of the nesticid species discussed in the text. The newly described species is in bold.

\begin{tabular}{|c|c|c|c|c|c|c|c|c|c|c|c|c|c|c|c|c|}
\hline No. & Species & 1 & 2 & 3 & 4 & 5 & 6 & 7 & 8 & 9 & 10 & 11 & 12 & 13 & 14 & 15 \\
\hline 1 & Dbae_Domitius_baeticus & & & & & & & & & & & & & & & \\
\hline 2 & Dluq_Domitius_luquei & 0.142 & & & & & & & & & & & & & & \\
\hline 3 & Dlus_Domitius_lusitanicus & 0.135 & 0.135 & & & & & & & & & & & & & \\
\hline 4 & D213_Domitius_menozzii & 0.140 & 0.146 & 0.119 & & & & & & & & & & & & \\
\hline 5 & $\begin{array}{l}\text { D555_Domitius_culsu sp. } \\
\text { nov. }\end{array}$ & 0.167 & 0.144 & 0.133 & 0.121 & & & & & & & & & & & \\
\hline 6 & Dsbo_Domitius_sbordonii & 0.181 & 0.176 & 0.167 & 0.181 & 0.185 & & & & & & & & & & \\
\hline 7 & $\begin{array}{l}\text { D557_Domitius_ } \\
\text { speluncarum }\end{array}$ & 0.162 & 0.144 & 0.121 & 0.121 & 0.071 & 0.190 & & & & & & & & & \\
\hline 8 & N214_Nesticus_cellulanus & 0.172 & 0.174 & 0.151 & 0.190 & 0.181 & 0.176 & 0.172 & & & & & & & & \\
\hline 9 & $\begin{array}{l}\text { K566_Kryptonesticus_ } \\
\text { dimensis }\end{array}$ & 0.156 & 0.151 & 0.135 & 0.144 & 0.165 & 0.172 & 0.146 & 0.121 & & & & & & & \\
\hline 10 & $\begin{array}{l}\text { K211_Kryptonesticus_ } \\
\text { eremita }\end{array}$ & 0.149 & 0.156 & 0.142 & 0.156 & 0.169 & 0.169 & 0.162 & 0.117 & 0.078 & & & & & & \\
\hline 11 & $\begin{array}{l}\text { C162_Carpathonesticus_ } \\
\text { fodinarum }\end{array}$ & 0.169 & 0.153 & 0.153 & 0.176 & 0.178 & 0.172 & 0.167 & 0.085 & 0.089 & 0.108 & & & & & \\
\hline 12 & $\begin{array}{l}\text { C166_Carpathonesitcus_ } \\
\text { lotriensis }\end{array}$ & 0.144 & 0.160 & 0.146 & 0.162 & 0.190 & 0.176 & 0.190 & 0.112 & 0.094 & 0.101 & 0.069 & & & & \\
\hline 13 & $\begin{array}{l}\text { Tobc_Typhlonesticus_ } \\
\text { obcaecatus }\end{array}$ & 0.197 & 0.178 & 0.167 & 0.165 & 0.178 & 0.176 & 0.181 & 0.149 & 0.156 & 0.158 & 0.140 & 0.142 & & & \\
\hline 14 & $\begin{array}{l}\text { T167_Typhlonesticus_ } \\
\text { idriacus }\end{array}$ & 0.181 & 0.174 & 0.167 & 0.183 & 0.192 & 0.197 & 0.185 & 0.142 & 0.156 & 0.165 & 0.149 & 0.156 & 0.096 & & \\
\hline 15 & $\begin{array}{l}\text { Tmor_Typhlonesticus_ } \\
\text { morisii }\end{array}$ & 0.174 & 0.174 & 0.174 & 0.181 & 0.199 & 0.208 & 0.181 & 0.183 & 0.160 & 0.183 & 0.176 & 0.174 & 0.117 & 0.124 & \\
\hline 16 & $\begin{array}{l}\text { G601_Gaucelmus_ } \\
\text { augustinus }\end{array}$ & 0.229 & 0.229 & 0.227 & 0.222 & 0.245 & 0.243 & 0.236 & 0.252 & 0.211 & 0.238 & 0.240 & 0.233 & 0.249 & 0.254 & 0.247 \\
\hline
\end{tabular}


it is possible to speculate that $D$. sbordonii represents a basal element within the genus Domitius, possibly still carrying the ancestral characters of the older forebear of the European nesticids.

\section{Conclusions}

All Italian species of the genus Domitius appear to be highly adapted to a permanent life in the subterranean environment, showing eye reduction and lack of body pigmentation. They further present a localized distribution, with distinct genetic and morphological differences between the species living in the Northern and Central areas of the Apennines. At the same time a close affinity with the species distributed in the Iberian Peninsula is observed. Such features, together with a high genetic $p$-distance among the species (Table 2), suggests a potentially complex evolutionary history of the genus Domitius that still needs to be properly explored (see also Ribera, 2018).

Because of their apparent similarities in habitus and female genitalia, $D$. culsu sp. nov has previously been mistaken for $D$. speluncarum and ignored as a distinct species by previous arachnologists. A detailed molecular and morphological analysis of both sexes of $D$. culsu sp. nov carried out in this work supports the validity of the new species and its close relationship with the other Domitius species from the same geographical area. Its potential susceptibility to external disturbance, and extremely limited distribution, makes $D$. culsu sp. nov of interest for conservation.

Finding a new nesticid species in Italy further suggests that our knowledge on the diversity of the family Nesticidae in Southern Europe is still far from complete. Further collections along the Italian peninsula will probably lead to the discovery of other highly-specialized nesticid species allowing a deeper and more precise understanding of the spider cave fauna in Italy and in the Mediterranean area.

\section{ACKNOWLEDGMENTS.}

Many thanks to Leonardo Latella and Roberta Salmaso for providing the use of microscopes and other facilities at the Natural History Museum of Verona, and for taking care of the juvenile samples under study. Thanks to Shuqiang $\mathrm{Li}$ (Chinese Academy of Sciences, Beijing) for supporting the molecular analysis of the samples, and to Domenico Rutigliano for his suggestions in choosing the name of the species. I am particularly grateful to Daniele Avesani for his important help in the field, which eventually led to the collection of the holotype male. I am equally thankful to all the people who kindly contributed in the field collection of the samples, or provided useful data and advice during the preparation of the article: Rodolfo Ballarin, Roberto Battiston, Manuele Gaiga, Giulio Gardini, Kadir B. Kunt, Augustin Nae, Paolo Pantini, Leonardo Piccini, Sara Pesenato, Antonio Scupola, Stefano Taiti, Alessio Trotta, Marco Valle, Stefano Vanni, and Simone Zannotti. Elena Ballarin kindly prepared the drawings used in the article. The English text of an early version of the work was edited by Victoria Smith (Canterbury Museum, New Zealand). I thank the three anonymous reviewers whose comments have helped to improve the manuscript. This work was supported by the "Prof. Sandro Ruffo" grant, Municipality of Verona. Molecular analysis of the samples was supported by the National Natural Sciences Foundation of China (NSFC- 31530067).

\section{References}

Ballarin, F., and Li, S., 2018, Diversification in tropics and subtropics following the mid-Miocene climate change: A case study of the spider genus Nesticella: Global Change Biology, v. 24, p. 577-591, doi: 10.1111/gcb.13958.

Brignoli, P.M., 1971, Note su ragni cavernicoli italiani (Araneae): Fragmenta Entomologica, p. 121-229.

Brignoli, P.M., 1979, Ragni d'Italia XXXI. Specie cavernicole nuove o interessanti (Araneae):. Quaderni del Museo di Speleologia “V. Rivera”, v. 5, no. 10, p. 1-48.

Brignoli, P.M., 1985, Aggiunte e correzioni al "Catalogo dei ragni cavernicoli italiani”: Memorie del Museo Civico di Storia Naturale di Verona, serie 2, v. 4, p. 51-64.

Culver D.C., and Pipan T., 2009, The Biology of Caves and Other Subterranean Habitats: Oxford, UK: Oxford University Press, p. 256.

Dresco, E., 1966, Étude de quelques espèces d'araignées du genre Nesticus (fam. Nesticidae): Annales de Spéléologie, v. 21, p. 795-813.

GenBank, 2018, GenBank sequence database: Available at: https://www.ncbi.nlm.nih.gov/genbank/, [accessed August, 2018].

Hall, T., 1999, BioEdit: a user friendly biological sequence alignment editor and analysis program for Windows 95/98/NT: Nucleic Acids Symposium Series, v. 41, p. 95-98.

Katoh, K., and Standley, D.M., 2013, MAFFT multiple sequence alignment software version 7: improvements in performance and usability: Molecular Biology and Evolution, v. 30, p. 772-780, https://doi.org/10.1093/molbev/mst010.

Kritscher, E., 1958, Araneen aus den Picentinischen Bergen: Memorie del Museo Civico di Storia Naturale di Verona, v. 6, p. 313-320.

Lanza, B, 1961, La fauna cavernicola della Toscana: Rassegna Speleologica Italiana, v. 13, no. 2, p. 23-51.

Lin, Y.C., Ballarin, F. and Li, S.Q., 2016, A survey of the spider family Nesticidae (Arachnida, Araneae) in Asia and Madagascar, with the description of forty-three new species: ZooKeys v. 627, p. 1-168. https://doi.org/10.3897/zookeys.627.8629

Mammola, S., and Isaia, M., 2017, Spiders in caves: Proceedings of the Royal Society B: Biological Sciences, v. 284: 20170193, https://doi. org/10.1098/rspb.2017.0193.

Miller, M.A., Pfeiffer, W., and Schwartz, T., 2010, Creating the CIPRES Science Gateway for inference of large phylogenetic trees: Proceedings of the Gateway Computing Environments Workshop (GCE), 14 Nov. 2010, New Orleans, LA, p. 1-8, https://doi.org/10.1109/ GCE.2010.5676129.

Pantini P. \& Isaia M. 2019. Araneae.it: the online Catalog of Italian spiders with addenda on other Arachnid Orders occurring in Italy (Arachnida: Araneae, Opiliones, Palpigradi, Pseudoscorpionida, Scorpiones, Solifugae). Fragmenta Entomologica 51 (2): 127-152. Available on line at www.araneae.it [accessed February 2020]. https://doi.org/10.4081/fe.2019.374. 
Pavlek, M., and Ribera, C. 2017, Kryptonesticus deelemanae gen. et sp. nov. (Araneae, Nesticidae), with notes on the Mediterranean cave species: European Journal of Taxonomy, 262, p. 1-27, https://doi.org/10.5852/ejt.2017.262.

Ribera, C., 2018, A new genus of nesticid spiders from western European Peninsulas (Araneae, Nesticidae): Zootaxa, v. 4407, p. 229-240, https://doi.org/10.11646/zootaxa.4407.2.4.

Stamatakis, A., 2014, RAxML version 8: a tool for phylogenetic analysis and post-analysis of large phylogenies: Bioinformatics, v. 30 , p. 1312-1313, https://doi.org/10.1093/bioinformatics/btu033.

Tamura, K., Stecher, G., Peterson, D., Filipski, A., and Kumar, S., 2013, MEGA6: Molecular Evolutionary Genetics Analysis version 6.0: Molecular Biology and Evolution, v. 30, p. 2725-2729, https://doi.org/10.1093/molbev/mst197,

World Spider Catalog, 2020, World Spider Catalog. Version 21.0: Natural History Museum Bern, available at: http://wsc.nmbe.ch, [accessed February, 2020], doi: 10.24436/2.

Zangheri, P., 1966, Repertorio sistematico e topografico della flora e fauna vivente e fossile della Romagna, Tomo II - Regno Animale. Museo Civico di Storia Naturale di Verona: Memorie Fuori Serie n¹, Stamperia Valdonega, Verona, p. 854 